\title{
Anti-VEGFR2 therapy delays growth of preclinical pediatric tumor models and enhances anti-tumor activity of chemotherapy
}

\section{Caitlin D. Lowery ${ }^{1}$, Wayne Blosser ${ }^{1}$, Michele Dowless ${ }^{1}$, Matthew Renschler ${ }^{1}$, Lisa V. Perez ${ }^{1}$, Jennifer Stephens ${ }^{1}$, Bronislaw Pytowski ${ }^{1}$, Heather Wasserstrom ${ }^{1}$, Louis F. Stancato ${ }^{1}$ and Beverly Falcon ${ }^{1}$}

${ }^{1}$ Eli Lilly and Company, Lilly Corporate Center, Indianapolis, IN, USA

Correspondence to: Beverly Falcon, email: falcon_beverly_l@lilly.com

Keywords: angiogenesis; pediatric cancer; VEGFR2; ramucirumab; DC 101

Received: May 24, $2019 \quad$ Accepted: July 21, $2019 \quad$ Published: September 17, 2019

Copyright: Lowery et al. This is an open-access article distributed under the terms of the Creative Commons Attribution License 3.0 (CC BY 3.0), which permits unrestricted use, distribution, and reproduction in any medium, provided the original author and source are credited.

\section{ABSTRACT}

Vascular endothelial growth factor receptor 2 (VEGFR2) is an attractive therapeutic target in solid malignancies due to its central role in tumor angiogenesis. Ramucirumab (Cyramza ${ }^{\circledR}$, LY3009806) is a human monoclonal antibody specific for VEGFR2 approved for several adult indications and currently in a phase 1 clinical trial for pediatric patients with solid tumors (NCT02564198). Here, we evaluated ramucirumab in vitro and the anti-murine VEGFR2 antibody DC101 in vivo with or without chemotherapy across a range of pediatric cancer models. Ramucirumab abrogated in vitro endothelial cord formation driven by cancer cell lines representing multiple pediatric histologies; this response was independent of the origin of the tumor cell-line. Several pediatric cancer mouse models responded to single agent DC101mediated VEGFR2 inhibition with tumor growth delay. Preclinical stable disease and partial xenograft regressions were observed in mouse models of Ewing's sarcoma, synovial sarcoma, neuroblastoma, and desmoplastic small round cell tumor treated with DC101 and cytotoxic chemotherapy. In contrast, DC101 treatment in osteosarcoma models had limited efficacy alone or in combination with chemotherapeutics. Our data indicate differential efficacy of targeting the VEGFR2 pathway in pediatric models and support the continued evaluation of VEGFR2 inhibition in combination with cytotoxic chemotherapy in multiple pediatric indications.

\section{INTRODUCTION}

Though survival rates for pediatric cancer patients have improved dramatically since the early 1960s, cancer remains the leading cause of disease-related death in children and adolescents [1]. Following first-line therapy, approximately $25 \%$ of pediatric cancer patients will experience a relapse which generally proves fatal $[2,3]$. In addition, nearly two-thirds of pediatric cancer survivors experience chronic, debilitating conditions and even secondary cancers resulting from aggressive treatment paradigms [4]. Despite dose-intensification of chemotherapy and focused efforts on understanding the molecular underpinnings of pediatric tumor types in the hopes of identifying therapeutic targets, survival rates have plateaued in recent years [5]. Therefore, identification and preclinical evaluation of novel targeted therapies in relevant pediatric model systems is necessary to support and better inform subsequent clinical investigation of these agents in pediatric indications.

The vascular endothelial growth factor (VEGF) family consists of five ligands (placental growth factor [PIGF] and VEGF-A, -B, -C, and -D) and three receptors (VEGFR1, VEGFR2, and VEGFR3) [6, 7]. Aberrant activation of VEGFR2 on endothelial cells by tumor cellsecreted VEGF-A drives angiogenesis, the development of new blood vessels from existing vessels. This new blood vessel growth supports tumor progression, local invasion, and metastasis $[8,9]$. Inhibition of the VEGF pathway in cancer is thought to not only reduce the total number 
of vessels to support tumor growth, but also improve the function of vessels within the tumor, thereby more effectively delivering other anti-cancer therapeutics [10]. Because of the multifaceted effects on tumor vessels, the VEGF-A:VEGFR2 signaling axis has been pursued as a therapeutic target in adult solid tumors with approvals across a number of tumor histologies [11-13]. Preclinical and clinical studies have demonstrated that small molecule inhibitors of the VEGF pathway have anti-tumor activity in some pediatric malignancies; however, it is still unclear which pediatric indications may receive the most benefit from anti-VEGFR2 therapy, either alone or in combination with chemotherapy [14-18].

Ramucirumab (Cyramza ${ }^{\circledR}$, LY3009806) is a fully human monoclonal antibody which specifically binds to and blocks the activation of VEGFR2 by its ligands VEGF-A, -C, and -D [19]. Currently, ramucirumab is FDA-approved for the treatment of advanced gastric or GE junction adenocarcinoma alone or in combination with paclitaxel; metastatic colorectal cancer in combination with FOLFIRI; metastatic non-small cell lung cancer in combination with docetaxel; and as a single agent in hepatocellular carcinoma patients with high alpha fetoprotein levels [20]. For pediatric patients with solid tumors, a dose-finding phase I trial for ramucirumab is currently underway (NCT02564198). Here, we tested ramucirumab or the anti-mouse VEGFR2 antibody DC101 (a ramucirumab surrogate for in vivo studies) in multiple pediatric cancer cell lines and xenograft mouse models with the goal of identifying specific pediatric indications that may respond to ramucirumab-mediated VEGFR2 inhibition.

\section{RESULTS}

\section{Pediatric cancer cell lines produce ligands for VEGFR2}

To first establish the expression patterns of VEGFR2 and its associated ligands in our pediatric cancer models, we profiled a panel of 11 pediatric cancer cell lines representing neuroblastoma (IMR-32, KELLY, SH-SY5Y), retinoblastoma (Y79), osteosarcoma (HOS, Saos-2, SJSA1), rhabdomyosarcoma (SJCRH30 [alveolar RMS], RD [embryonal RMS]), malignant rhabdoid tumor (A-204), and Ewing's sarcoma (RD-ES) for VEGFR2 protein expression (Figure 1A). As expected, VEGFR2 was absent from the majority of cancer cell lines and detected in only 3 out of the 11 cell lines (KELLY, SJCRH30, and $\mathrm{RD})$ at much lower levels than the VEGF-A-stimulated endothelial colony forming cell (ECFC) control.

Tumor cells can activate VEGFR2 on endothelial cells (and thus promote neovascularization) through production and secretion of VEGF-A, -C, and -D. We previously determined that the neuroblastoma cell lines (IMR-32, KELLY, and SH-SY5Y) produce VEGF-A, -C, and -D in co-culture conditions [21]. We determined that these ligands were also present in media collected from each of the 9 additional non-neuroblastoma cell lines grown in co-culture conditions (Figure 1B). VEGF-A production was the most varied, from over $9000 \mathrm{pg} / \mathrm{mL}$ detected in SJSA-1 osteosarcoma media to approximately $525 \mathrm{pg} / \mathrm{mL}$ in the SJCRH30 alveolar RMS media. Conversely, VEGF-C levels were generally below 1000 $\mathrm{pg} / \mathrm{mL}$ and VEGF-D was more uniformly expressed at concentrations below $400 \mathrm{pg} / \mathrm{mL}$ across all cell lines tested.

\section{Ramucirumab impedes both VEGF- and tumor- driven cord formation}

We next tested the ability of pediatric cancer cell lines to support in vitro endothelial cord formation [22]. As adipocyte derived stem cells (ADSCs) and ECFCs grown together in co-culture conditions were shown to produce a minimal amount of VEGF-A (approximately $40 \mathrm{pg} / \mathrm{mL}$ ) [22], exogenous VEGF-A was used to drive cord formation in tumor cell-free wells. Indeed, the proangiogenic factors secreted by the panel of pediatric cancer cell lines could promote the formation of cords comparable to those achieved in VEGF-A-driven assays (Figure 2). Inhibition of VEGFR2 using the monoclonal antibody ramucirumab $\left(\right.$ Cyramza $^{\circledR}$, LY3009806) significantly blunted cord formation promoted by either tumor cell lines or VEGF-A, as measured by a significant reduction in total tube area ( $\geq 65 \%$ ) with treatment compared to controls (Figure 2). Ramucirumab-mediated reduction in tumor-driven cord formation was not a result of cancer cell death (Supplementary Figure 1), consistent with the lack of target expression in the majority of tumor cell lines tested.

\section{DC101 is active as monotherapy or in combination with chemotherapy in a subset of pediatric bone and soft tissue tumor models}

As ramucirumab does not cross react with mouse VEGFR2, the rat anti-mouse VEGFR2 antibody DC101 [23] was used to treat 8 cell line-derived (CDX) and 21 patient-derived (PDX) xenograft mouse models representing 10 extracranial pediatric solid tumor types (Table 1 and Supplementary Table 1). Animals were treated with $20 \mathrm{mg} / \mathrm{kg}$ DC101 twice weekly for up to 4 weeks, either as a single agent or in combination with chemotherapies typically used for pediatric cancer patients.

We observed that single agent DC101 significantly reduced tumor volumes compared to untreated animals in 13 of the 29 (45\%) evaluated pediatric cancer models, though the responses were generally limited to tumor growth delay resulting in lower average tumor volume but not stable disease or tumor regression (Table 1). Three RMS models, one alveolar (SJCRH30) and two embryonal (RD and CTG-1213), responded to 
chemotherapy and DC101 as single agents. When the two drugs were combined, a significantly greater reduction in tumor volume was observed and some individual animals achieved stable disease (Figure 3A, Table 1). Similarly, all three in vivo mouse models of neuroblastoma were sensitive to DC101 monotherapy (Figure 3B, Table 1). While the reduction in KELLY xenograft volumes in the combination treatment arm could be attributed to DC101 alone (limited effects of doxorubicin single agent was observed in this model), improved responses with combination treatment were noted in the other two neuroblastoma models. Individual animals bearing IMR32 or SH-SY5Y xenografts achieved stable disease or partial response and one animal with an SH-SY5Y tumor demonstrated a complete response when treated with DC101 and doxorubicin.

The synovial sarcoma PDX model CTG-1173 was largely nonresponsive to DC101 monotherapy; however, 8/10 animals had tumor regression following gemcitabine/ docetaxel treatment. Remarkably, this response was significantly enhanced with the addition of DC101 to gemcitabine/docetaxel (Figure 4A, top; Table 1). Another synovial sarcoma PDX model (CTG-0331) responded to both single agent DC101 and doxorubicin with a tumor growth delay (Figure 4A, bottom). The combination treatment resulted in a pronounced tumor growth delay which was sustained for approximately 3 weeks following the end of treatment. Both desmoplastic small round cell tumor (DSCRT) PDX models responded to single agent treatment with either DC101 or chemotherapy (either cyclophosphamide or doxorubicin) (Figure 4B). Combination treatment of DC101 and cyclophosphamide resulted in stable disease in animals bearing CTG-1458 tumors and DC101 also enhanced the anti-tumor activity of doxorubicin in the CTG-0926 PDX model.

Several Ewing's sarcoma models responded to in vivo VEGFR2 inhibition (Tables 1 and 2). Significant single agent activity of DC101 was observed in CTG0994, which was not further enhanced with the addition of doxorubicin (Figure 5A). Stable disease was observed in the CTG-0816 Ewing's sarcoma PDX model following DC101 monotherapy and combination with doxorubicin resulted in two animals achieving a partial response ( $>50 \%$ regression) (Figure $5 \mathrm{~B})$. The combination of DC101 and doxorubicin was superior to either single agent in animals with CTG-0142 Ewing's sarcoma xenografts (Figure 5C). Six additional PDX models of Ewing's sarcoma were evaluated in an ' $\mathrm{n}$ of 1 ' design (Table 2). One model, CTG-1651, responded to both single agent DC101 and the combination of DC101 with doxorubicin with stable disease $(8.4 \% \Delta \mathrm{T} / \mathrm{C}$ and $12 \%$ regression, respectively). The $\mathrm{CTG}-1663$ model responded to DC101 monotherapy, but this response was not enhanced with the addition of doxorubicin.

\section{A}
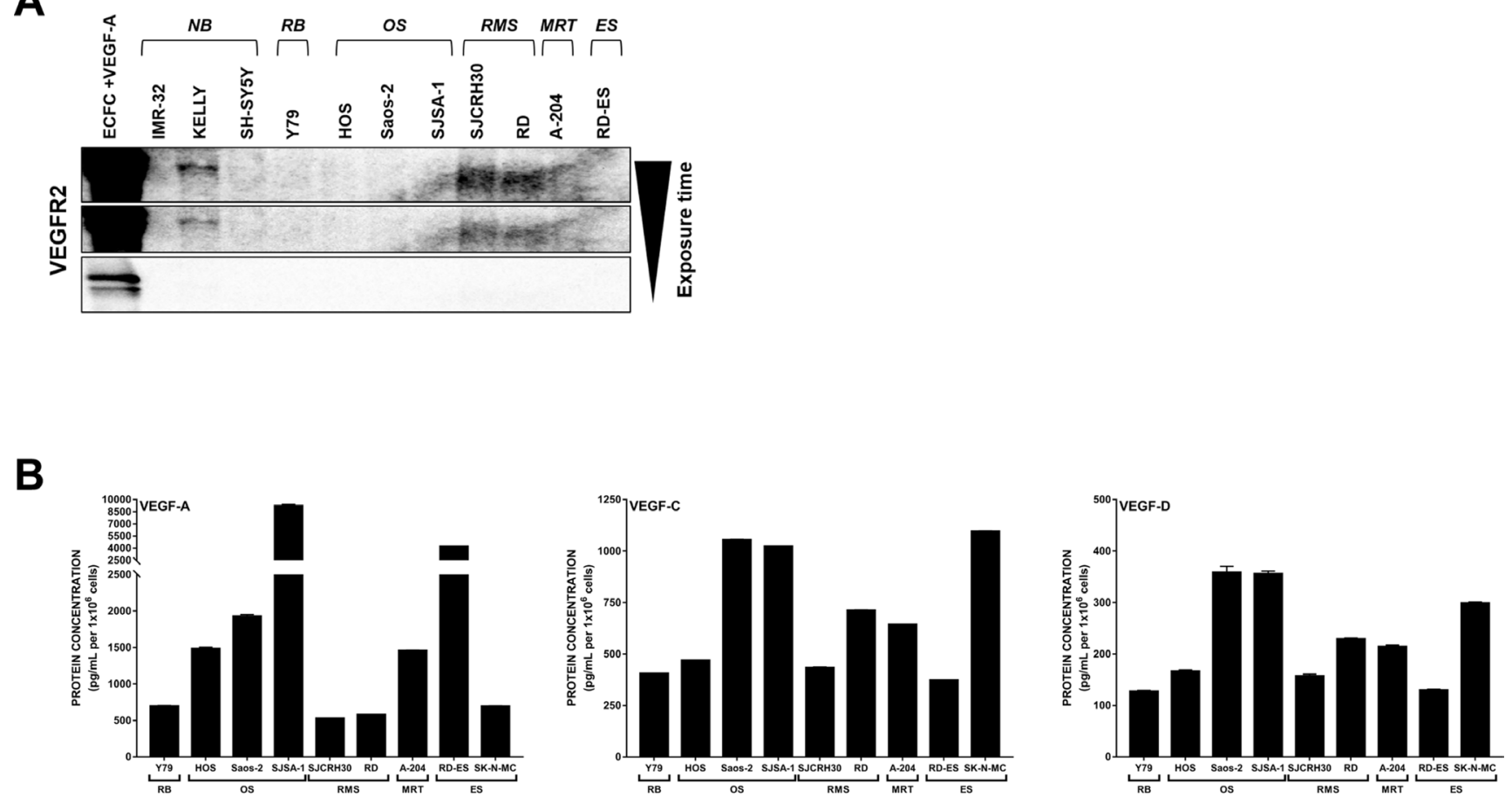

Figure 1: Expression of VEGFR2 and associated VEGFs are detected in pediatric cancer cell lines. (A) Eleven pediatric cancer cell lines were evaluated for endogenous VEGFR2 protein expression. (B) Endogenous levels of VEGF-A (left), -C (middle), and -D (right) protein produced by 9 pediatric cancer cell lines in co-culture conditions were assayed by ELISA. Error bars represent SEM. Note the bro ken y-axis for VEGF-A. Abbreviations: ECFC, endothelial colony forming cell; NB, neuroblastoma; RB, retinoblastoma; OS, osteosarcoma; RMS, rhabdomyosarcoma; MRT, malignant rhabdoid tumor; ES, Ewing's sarcoma. 
Three models (CTG-2003, -2113, and -2174) were most sensitive to single agent doxorubicin treatment, while CTG-0143 did not respond to either DC101 or doxorubicin monotherapy and only demonstrated a slight reduction in tumor volume with the combination.

Additional pediatric tumor models were also interrogated for their response to DC101 with or without chemotherapy (Table 1). Only 1 out of 4 osteosarcoma models (CTG-0241) had a significant reduction in tumor growth with DC101 treatment alone (Figure 5D). Two additional osteosarcoma models demonstrated some reduction in tumor growth with DC101 monotherapy, but these responses were not statistically significant (Figure 5E and 5F). Combination treatment of DC101 and doxorubicin in these models did not significantly reduce tumor growth compared to vehicle and doxorubicin alone. A-204 malignant rhabdoid tumor,
Y79 retinoblastoma, CTG-1072 hepatoblastoma, and CTG-1094 undifferentiated sarcoma models responded to DC101 and/or chemotherapy alone, but the combination did not improve response (Table 1).

\section{Two preclinical mouse models respond to DC101 following initial treatment with doxorubicin}

We explored the potential for DC101 to act as a maintenance therapy in a subset of PDX models of several histologies (Supplementary Table 1). Following 4 weeks of doxorubicin treatment, animals were split into two groups - one receiving no treatment and one receiving DC101 monotherapy. Two out of 14 models assessed responded to subsequent treatment with DC101 (Supplementary Figure 2). Pronounced inhibition of tumor growth was observed in the CTG-0331 synovial
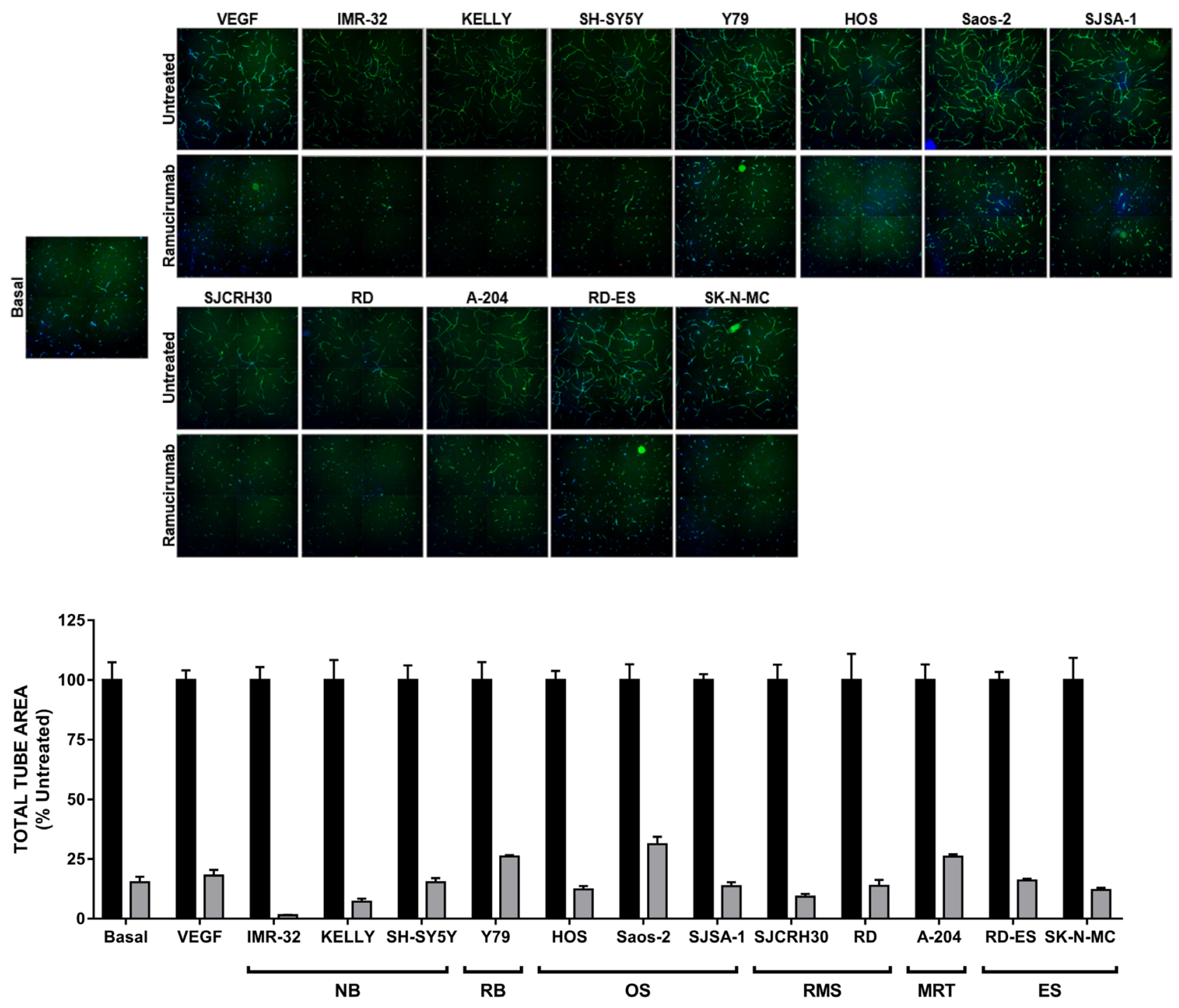

Figure 2: Ramucirumab blocks both VEGF-A- and pediatric tumor cell-driven cord formation in vitro. (Top) Representative images of cords from each condition are shown. (Bottom) Total tube area of VEGF-A- and tumor cell-driven cords is presented, with data for each cell line normalized to its respective untreated control. Black bars: untreated; gray bars: treated with $10 \mu \mathrm{g} /$ $\mathrm{mL}$ ramucirumab. Error bars represent SEM. 
Table 1: Summary of in vivo pediatric tumor model studies

\begin{tabular}{|c|c|c|c|c|c|c|c|c|c|}
\hline \multirow{3}{*}{$\begin{array}{l}\text { Model } \\
\text { SJCRH30 }\end{array}$} & \multirow{3}{*}{$\begin{array}{c}\begin{array}{c}\text { Xenograft } \\
\text { type }\end{array} \\
\text { CDX }\end{array}$} & \multirow{3}{*}{$\begin{array}{l}\text { Tumor type } \\
\text { alveolar RMS }\end{array}$} & \multirow{3}{*}{$\begin{array}{c}\begin{array}{c}\text { Analysis } \\
\text { day }\end{array} \\
38\end{array}$} & \multicolumn{2}{|c|}{ Chemotherapy } & \multirow{2}{*}{$\frac{\text { DC101 }}{\% \Delta}$} & \multirow{2}{*}{\multicolumn{2}{|c|}{$\begin{array}{l}\text { Chemo Combination } \\
/ \mathrm{C} \text { or regression on } \\
\text { analysis day }\end{array}$}} & \multirow{3}{*}{$\begin{array}{c}\begin{array}{c}\text { Combination } \\
\text { effect }^{\wedge}\end{array} \\
\text { Additive }\end{array}$} \\
\hline & & & & \multirow{2}{*}{$\begin{array}{c}\text { Agent } \\
\text { Doxorubicin }\end{array}$} & \multirow{2}{*}{$\begin{array}{c}\text { Dose, Schedule } \\
5 \mathrm{mg} / \mathrm{kg}, \text { Q7Dx4 }\end{array}$} & & & & \\
\hline & & & & & & 26 & 57 & $15^{\dagger+}$ & \\
\hline $\mathrm{RD}$ & $\mathrm{CDX}$ & embryonal RMS & 64 & Doxorubicin & $5 \mathrm{mg} / \mathrm{kg}, \mathrm{Q} 7 \mathrm{Dx} 4$ & 40 & 20 & $12^{\dagger}$ & $\begin{array}{l}\text { Less than } \\
\text { additive }\end{array}$ \\
\hline CTG-1213 & PDX & embryonal RMS & 26 & Actinomycin D & $\begin{array}{l}0.25 \mathrm{mg} / \mathrm{kg} \\
\quad \mathrm{D} 0,21\end{array}$ & 46 & 62 & $27^{\ddagger}$ & Unknown \\
\hline CTG-0926 & PDX & DSRCT & 28 & Doxorubicin & $5 \mathrm{mg} / \mathrm{kg}$, Q7Dx4 & 60 & 42 & $22^{\dagger \neq}$ & Unknown \\
\hline CTG-1458 & PDX & DSRCT & 35 & Cyclophosphamide & $\begin{array}{c}100 \mathrm{mg} / \mathrm{kg} \\
\text { Q7Dx4 }\end{array}$ & 50 & 42 & $\mathbf{8}^{\dagger+}$ & Additive \\
\hline RD-ES & $\mathrm{CDX}$ & Ewing's sarcoma & 28 & Doxorubicin & $5 \mathrm{mg} / \mathrm{kg}, \mathrm{Q} 7 \mathrm{Dx} 4$ & 69 & 28 & $-30^{\text {柿 }}$ & Additive \\
\hline CTG-0142 & PDX & Ewing's sarcoma & 28 & Doxorubicin & $5 \mathrm{mg} / \mathrm{kg}$, Q7Dx4 & 44 & 38 & $11^{\text {t木 }}$ & Unknown \\
\hline CTG-0785 & PDX & Ewing's sarcoma & 18 & Doxorubicin & $5 \mathrm{mg} / \mathrm{kg}, \mathrm{Q} 7 \mathrm{Dx} 4$ & 37 & 46 & 41 & $\begin{array}{l}\text { Less than } \\
\text { additive }\end{array}$ \\
\hline CTG-0816 & PDX & Ewing's sarcoma & 35 & Doxorubicin & $5 \mathrm{mg} / \mathrm{kg}, \mathrm{Q} 7 \mathrm{Dx} 4$ & 3 & 3 & $-49^{\text {市 }}$ & $\begin{array}{l}\text { Less than } \\
\text { additive }\end{array}$ \\
\hline CTG-0994 & PDX & Ewing's sarcoma & 21 & Doxorubicin & $5 \mathrm{mg} / \mathrm{kg}, \mathrm{Q} 7 \mathrm{Dx} 4$ & 19 & 78 & $42^{\ddagger}$ & $\begin{array}{l}\text { Less than } \\
\text { additive }\end{array}$ \\
\hline CTG-1072 & PDX & hepatoblastoma & 17 & Cisplatin & $5 \mathrm{mg} / \mathrm{kg}, \mathrm{Q} 7 \mathrm{Dx} 4$ & 55 & 55 & 52 & No effect \\
\hline A-204 & $\mathrm{CDX}$ & $\begin{array}{c}\text { malignant } \\
\text { rhabdoid tumor }\end{array}$ & 52 & Doxorubicin & $5 \mathrm{mg} / \mathrm{kg}, \mathrm{Q} 7 \mathrm{Dx} 4$ & 62 & 33 & 31 & No effect \\
\hline IMR-32 & $\mathrm{CDX}$ & neuroblastoma & 70 & Doxorubicin & $3 \mathrm{mg} / \mathrm{kg}$, Q7Dx4 & 47 & 30 & $16^{\dagger \neq}$ & Additive \\
\hline KELLY & $\mathrm{CDX}$ & neuroblastoma & 49 & Doxorubicin & $2 \mathrm{mg} / \mathrm{kg}$, Q7Dx3 & 46 & 98 & $48^{\ddagger}$ & No effect \\
\hline SH-SY5Y & $\mathrm{CDX}$ & neuroblastoma & 52 & Doxorubicin & $5 \mathrm{mg} / \mathrm{kg}, \mathrm{Q} 7 \mathrm{Dx} 4$ & 25 & 10 & -28 & No effect \\
\hline CTG-0241 & PDX & osteosarcoma & 28 & Doxorubicin & $5 \mathrm{mg} / \mathrm{kg}, \mathrm{Q} 7 \mathrm{Dx} 4$ & 51 & 109 & 78 & No effect \\
\hline CTG-0242 & PDX & osteosarcoma & 28 & Doxorubicin & $5 \mathrm{mg} / \mathrm{kg}, \mathrm{Q} 7 \mathrm{Dx} 4$ & 56 & 9 & 21 & No effect \\
\hline CTG-0243 & PDX & osteosarcoma & 16 & Doxorubicin & $5 \mathrm{mg} / \mathrm{kg}, \mathrm{Q} 7 \mathrm{Dx} 4$ & 229 & 219 & $95^{\text {t木 }}$ & No effect \\
\hline CTG-1064 & PDX & osteosarcoma & 27 & Doxorubicin & $5 \mathrm{mg} / \mathrm{kg}, \mathrm{Q} 7 \mathrm{Dx} 4$ & 53 & 157 & $41^{\ddagger}$ & No effect \\
\hline Y79 & $\mathrm{CDX}$ & retinoblastoma & 44 & Doxorubicin & $5 \mathrm{mg} / \mathrm{kg}, \mathrm{Q} 7 \mathrm{Dx} 4$ & 16 & 18 & -11 & Unknown \\
\hline CTG-0331 & PDX & synovial sarcoma & 27 & Doxorubicin & $5 \mathrm{mg} / \mathrm{kg}$, Q7Dx4 & 22 & 36 & $7^{\ddagger}$ & No effect \\
\hline CTG-1173 & PDX & synovial sarcoma & 52 & $\begin{array}{l}\text { Gemcitabine } \\
\text { Docetaxel }\end{array}$ & $\begin{array}{c}60 \mathrm{mg} / \mathrm{kg}, \\
\text { Q7Dx4 } \\
6 \mathrm{mg} / \mathrm{kg}, \text { Q7Dx4 }\end{array}$ & 79 & -43 & $-64^{\dagger \neq}$ & Additive \\
\hline CTG-1094 & PDX & $\begin{array}{l}\text { undifferentiated } \\
\text { sarcoma }\end{array}$ & 17 & Doxorubicin & $5 \mathrm{mg} / \mathrm{kg}, \mathrm{Q} 7 \mathrm{Dx} 4$ & 45 & 44 & 53 & No effect \\
\hline
\end{tabular}

sarcoma model and tumor growth delay was noted in the CTG-0994 Ewing's sarcoma model when DC101 was administered following completion of the doxorubicin treatment interval.

Collectively, our in vivo data demonstrate that DC101-mediated VEGFR2 inhibition was sufficient to delay tumor growth in alveolar and embryonal RMS, DSRCT, Ewing's sarcoma, synovial sarcoma, and neuroblastoma. DC101 monotherapy enhanced the duration of tumor growth delay following an initial response to doxorubicin in one model of each synovial sarcoma and Ewing's sarcoma. We also observed that the concurrent administration of DC101 and chemotherapy improved the anti-tumor response compared to control and chemotherapy alone in mice bearing models of alveolar RMS, embryonal RMS, DSRCT, Ewing's 
sarcoma, neuroblastoma, and synovial sarcoma, but not osteosarcoma, hepatoblastoma, rhabdoid, or retinoblastoma.

\section{DISCUSSION}

The low incidence of molecular aberrations combined with the relative rarity of pediatric cancer and associated preclinical models often impedes the development and clinical evaluation of novel therapies specifically for pediatric indications $[5,24,25]$. Targeting the tumor microenvironment is a potential avenue to improve patient response to existing regimens consisting of chemotherapy and/or targeted agents with unique mechanisms-of-action. As VEGFR2 is a crucial mediator of tumor angiogenesis and is predominately expressed on the endothelium rather than tumors, it is a promising therapeutic target across different cancer types. Novel agents which target tumor angiogenesis have been assessed clinically across adult and pediatric

\section{A}
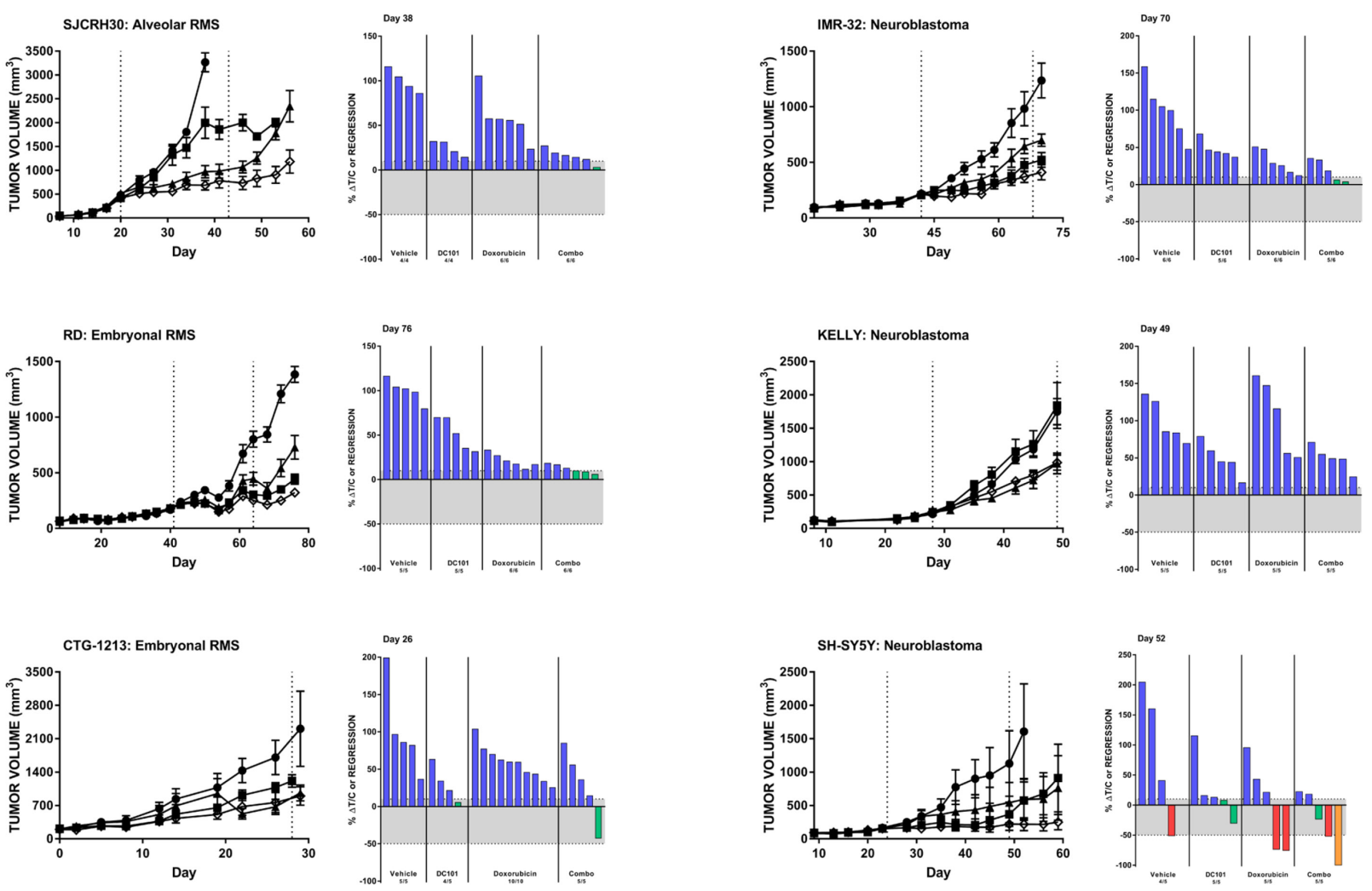

Figure 3: DC101 monotherapy delays tumor growth in pediatric mouse models of rhabdomyosarcoma (A) and (B) neuroblastoma. All animals were treated with control $(\bullet)$, DC101 $(\mathbf{\Delta})$, doxorubicin $(\mathbf{\square})$, or the combination $(\diamond)$. Animals were treated when tumors reached approximately $200 \mathrm{~mm}^{3}$. The treatment interval is represented by dotted vertical lines except where treatment began at Day 0 in which case the end of treatment is indicated by a single dotted line at Day 28. Error bars represent SEM. Waterfall plots were generated on the day indicated in the top left corner of the image (generally, the last day the majority of vehicle animals were still evaluable). Blue bars: progressive disease ( $\mathrm{PD} ; \geq 10 \% \Delta \mathrm{T} / \mathrm{C}$ ). Green bars: stable disease ( $\mathrm{SD} ;<10 \% \Delta \mathrm{T} / \mathrm{C}$ and $<50 \%$ regression). Red bars: partial regression (PR; $\geq 50 \%$ regression and tumor volume $\geq 14 \mathrm{~mm}^{3}$ ). Orange bars: complete regression (CR; tumor volume $<14 \mathrm{~mm}^{3}$ ). RMS: rhabdomyosarcoma. 
that the health of pediatric tumor cell lines was not affected by in vitro ramucirumab treatment despite the universal reduction in cord formation across all cell lines tested. This demonstrates the need for combination treatment of VEGFR2 pathway inhibition with a cytotoxic agent to hit both the tumor and the pathogenic tumor microenvironment. We did not expect DC101 alone to promote xenograft regression in our CDX models of pediatric cancer as it only targets the mouse receptor and considered stable disease or tumor growth delay to be indicative of DC101 monotherapy activity. Indeed, multiple pediatric tumor models met these criteria, including alveolar and embryonal RMS, DSRCT, Ewing's sarcoma, neuroblastoma, and synovial sarcoma and tumor regression was only observed when DC101 was combined with doxorubicin or another cytotoxic agent. Therefore, VEGFR2 inhibition via ramucirumab treatment may provide additional clinical benefit when added to other cytotoxic agents, including those used during pediatric cancer treatment such as vincristine, irinotecan, and temozolomide [5] or targeted agents with unique mechanisms-of-action currently being explored in the pediatric population. Ramucirumab and DC101 were active across multiple pediatric histologies, thus demonstrating the relatively tumor type-agnostic activity of VEGFR2 inhibition. However, there were some pediatric indications such as osteosarcoma that appeared less sensitive to

A
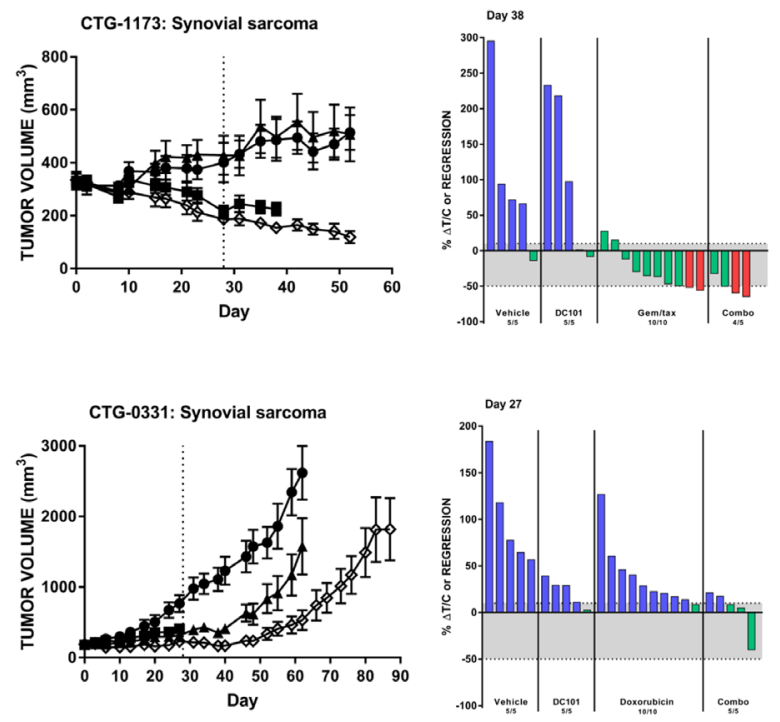

these combinations. The best combination partners for ramucirumab may vary across tumor types and between patients. In addition, tumors can employ one of multiple intrinsic or acquired escape mechanisms to circumvent the anti-tumor activity of VEGF pathway inhibitors [30-32]; however, detailing which of these mechanisms applies to each pediatric tumor model was beyond the scope of this study. Therefore, the efficacy of potential combinations as well as the identification of ramucirumab resistance would be best explored in a clinical setting.

To our knowledge, this preclinical study is the first exploring ramucirumab and DC101 in pediatric cancer models. Our data demonstrate that VEGFR2 inhibition, either as monotherapy or in combination with chemotherapy, promotes anti-tumor responses in several pediatric cancer models and further supports clinical investigation of ramucirumab in combination with other therapies for pediatric cancer patients.

\section{METHODS}

\section{Cell culture conditions}

All cell lines were purchased from the American Type Culture Collection (ATCC) or DSMZ and grown in the media recommended by the respective vendor. Cell lines were maintained at $37^{\circ} \mathrm{C}$ in $5 \% \mathrm{CO}_{2}$.

B
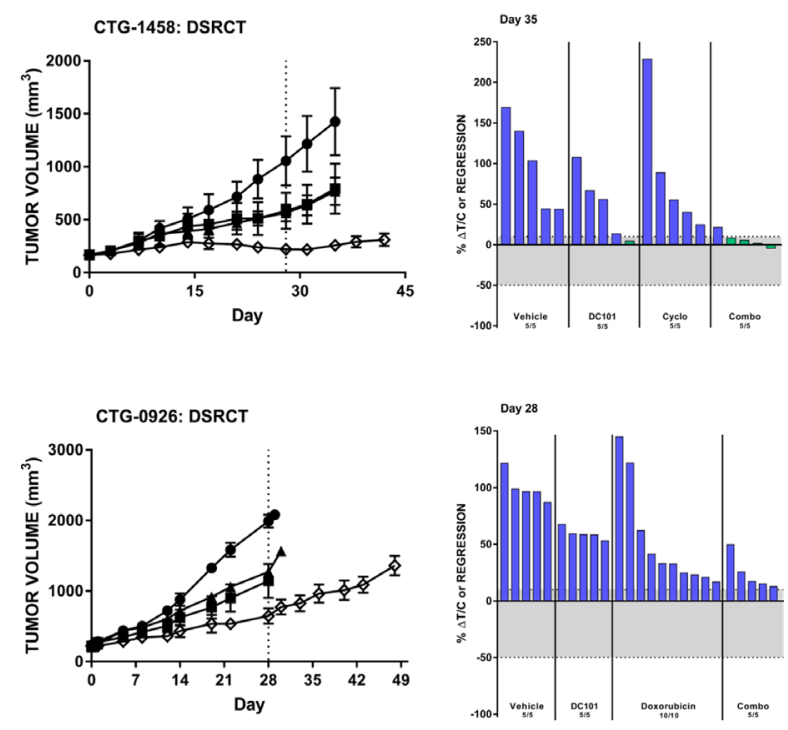

Figure 4: DC101 enhances the effects of chemotherapy in preclinical models of (A) synovial sarcoma and (B) DSRCT. All animals were treated with control $(\bullet)$, DC101 $(\mathbf{\Delta})$, chemotherapy ( $\mathbf{\square}$; noted in waterfall plot), or the combination $(\diamond)$ ). Treatment began at Day 0 and ended at Day 28 (dotted vertical line). For each panel, tumor growth curves are shown on the left and waterfall plots on the right. Error bars represent SEM. Waterfall plots were generated on the day indicated in the top left corner of the image (generally, the last day the majority of vehicle animals were still evaluable). Blue bars: progressive disease ( $\mathrm{PD} ; \geq 10 \% \Delta \mathrm{T} / \mathrm{C})$. Green bars: stable disease $(\mathrm{SD} ;<10 \% \Delta \mathrm{T} / \mathrm{C}$ and $<50 \%$ regression). Red bars: partial regression (PR; $\geq 50 \%$ regression and tumor volume $\geq 14 \mathrm{~mm}^{3}$ ). Abbreviations: DSRCT, desmoplastic small round cell tumor; Gem/tax, gemcitabine plus docetaxel. 
Table 2: Summary of Ewing's sarcoma 'n of 1' study results

\begin{tabular}{lccc}
\hline \multirow{2}{*}{ Model } & DC101 & Doxorubicin & Combination \\
\cline { 2 - 4 } & & \% $\mathbf{\Delta T / C}$ or regression* & \\
\hline CTG-0143 & 153 & 176 & 66.4 \\
CTG-1651 & 8.4 & 57.4 & -12.1 \\
CTG-1663 & 29.2 & 44 & 20.7 \\
CTG-2003 & 101 & 42.8 & 103 \\
CTG-2113 & 54.6 & 12.3 & 39.6 \\
CTG-2174 & 54.5 & 3.1 & 52.1 \\
\hline
\end{tabular}

*at end of treatment (Day 28) or date of sacrifice if prior to end of treatment.

\section{Test compound}

Ramucirumab (LY3009806, Eli Lilly and Company) was diluted in PBS at a stock concentration of $8.9 \mathrm{mg} / \mathrm{mL}$. The anti-murine VEGFR2 antibody DC101 (LY3180389, Eli Lilly and Company) was suspended in phosphatebuffered saline (PBS) for in vivo administration.

A
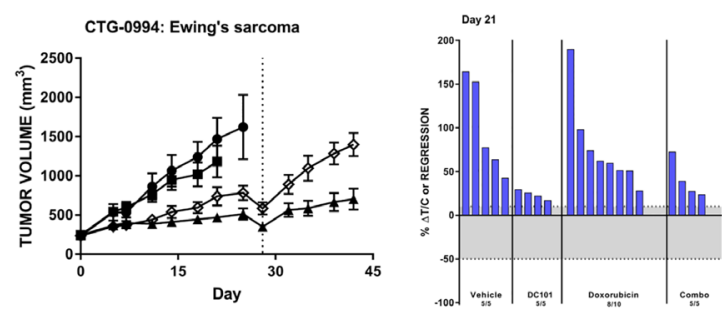

B

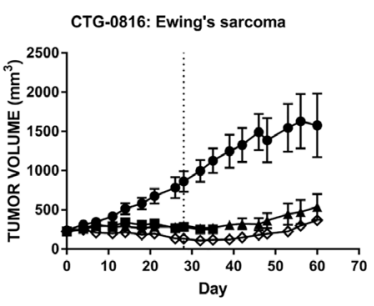

C

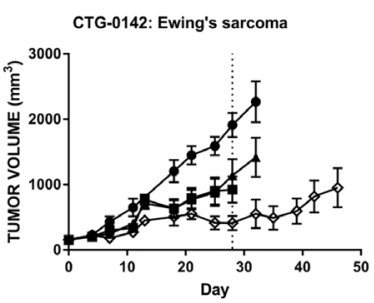

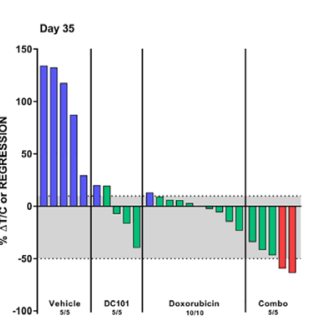

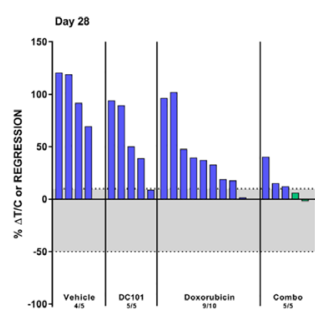

\section{Western blot analysis}

Cell lysis, SDS-PAGE, and immunoblotting were performed as previously described [21]. Cells pieces were lysed in 1\% SDS (Fisher BioReagents, cat\#BP2436-200) supplemented with 1x HALT protease and phosphatase inhibitor (ThermoFisher, cat\#78441). The

D
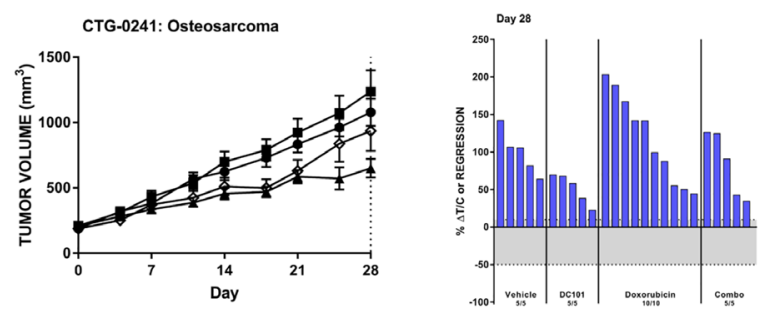

E
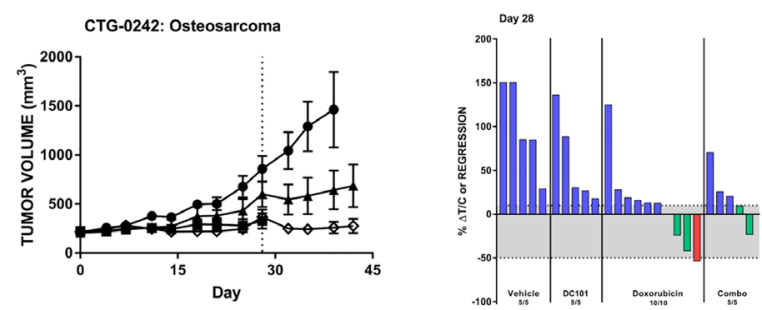

$\mathbf{F}$

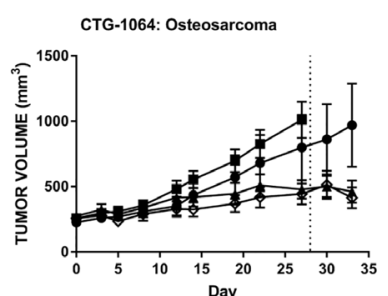

Figure 5: Preclinical models of Ewing's sarcoma and osteosarcoma respond to DC101 alone and in combination with cytotoxic chemotherapy. All animals were treated with control $(\bullet)$, DC101 $(\boldsymbol{\Delta})$, doxorubicin $(\boldsymbol{\square})$, or the combination $(\diamond)$. Treatment began at Day 0 and ended at Day 28 (dotted vertical line). For each panel, tumor growth curves are shown on the left and waterfall plots on the right. Error bars represent SEM. Waterfall plots were generated on the day indicated in the top left corner of the image (generally, the last day the majority of vehicle animals were still evaluable). Blue bars: progressive disease ( $\mathrm{PD} ; \geq 10 \% \Delta \mathrm{T} / \mathrm{C}$ ). Green bars: stable disease $\left(\mathrm{SD} ;<10 \% \Delta \mathrm{T} / \mathrm{C}\right.$ and $<50 \%$ regression). Red bars: partial regression (PR; $\geq 50 \%$ regression and tumor volume $\geq 14 \mathrm{~mm}^{3}$ ). 
following antibodies were purchased from Cell Signaling Technology: VEGFR2 (cat\#2479), VEGFR2 Y1175 (cat\#2478), ERK1/2 (cat\#4695), and ERK1/2 T202/Y204 (cat\#4370). For protein assessment following ligand stimulation, cells were incubated with $10 \mathrm{ng} / \mathrm{mL}$ VEGF-A (R\&D Systems cat\#293VE) for 10 minutes prior to harvest and lysate generation.

\section{Quantification of ligand production by cancer cell lines}

Pediatric cancer cell lines were grown in adipocyte derived stem cell (ADSC) conditioned media, which are the co-culture conditions for cord formation. Conditioned media was collected at the 48 hour timepoint and analyzed using the MSD Multi-Spot Assay System Angiogenesis Panel 1 (MSD, cat\#K15190D) per the manufacturers' instructions.

\section{In vitro cord formation assays}

Cord formation assays were performed as previously described [21, 22, 33]. Ramucirumab was used at a final concentration of $10 \mu \mathrm{g} / \mathrm{mL}$. VEGF-A (Invitrogen, cat\#PHC9394) was used at $10 \mathrm{ng} / \mathrm{mL}$ in wells without tumor cells to serve as a positive control for cord formation, as a previous study demonstrated that ADSCs and endothelial colony forming cells grown in co-culture conditions produce approximately $40-50 \mathrm{pg} / \mathrm{mL}$ VEGF-A and thus need exogenous ligand for cord formation [22]. In addition, the amount of VEGF-A contributed by ADSCs and ECFCs was assumed constant across all conditions tested.

Cell viability was assessed following completion of the cord formation assay using the CellTiter Glo ${ }^{\mathrm{TM}}$ (CTG) Luminescent Cell Viability Assay (Promega, cat\# G7571). Transwells containing tumor cells were removed and placed into a white, opaque bottom 96-well plate. Approximate volume was determined by measuring with a pipette, the appropriate volume of CTG reagent was added, and the CTG reagent/lysate solution was transferred to the white plate and read on a SpectraMax plate reader. For each cell line, luminescence was normalized to the average of the DMSO-treated control.

\section{In vivo evaluation of DC101}

Experiments involving animals were performed in accordance with American Association for Laboratory Animal Care institutional guidelines. In vivo studies using cell line-derived xenograft (CDX) models were approved by the Eli Lilly and Company Animal Care and Use Committee. In vivo experiments utilizing patient-derived xenograft (PDX) models designated by codes starting with 'CTG' were conducted at Champions Oncology (Hackensack, NJ, USA).
To evaluate DC101 and chemotherapy effects on CDX growth, cells were harvested during log phase growth and resuspended in Hank's Balanced Salt Solution (HBSS). Suspended cells were diluted 1:1 with BD Matrigel Matrix (cat\#356234; RD-ES, KELLY, IMR-32, SH-SY5Y) and $5 \times 10^{6}$ cells or $10 \times 10^{6}$ cells (RD-ES and $\mathrm{RD})$ were injected subcutaneously into the right flank of female athymic nude mice. When tumor volumes averaged $\sim 200 \mathrm{~mm}^{3}$, mice were randomized into treatment groups. Animals were given vehicle $\left(20 \%\right.$ Captisol $^{\mathrm{TM}}$ in water, pH 4), DC101, chemotherapy (doxorubicin, cisplatin, cyclophosphamide, or gemcitabine + docetaxel), or a combination of DC101 and chemotherapy. Combination partners were dependent on the tumor model. DC101 (20 $\mathrm{mg} / \mathrm{kg}$, ip) was administered twice weekly for up to 4 weeks. Chemotherapy was given for 4 weeks at the following dose and schedules: doxorubicin, $5 \mathrm{mg} / \mathrm{kg}$ (unless otherwise noted) once weekly (Q7D; iv); cisplatin, $4 \mathrm{mg} / \mathrm{kg}$ once weekly (Q7D; ip); cyclophosphamide, 100 $\mathrm{mg} / \mathrm{kg}$ once weekly (Q7D; ip); gemcitabine, $60 \mathrm{mg} / \mathrm{kg}$ once weekly (Q7D; ip) + docetaxel, $6 \mathrm{mg} / \mathrm{kg}$ once weekly (Q7D; ip). For DC101 maintenance therapy-related studies, animals received doxorubicin for 4 weeks. The doxorubicin group was then split into two equal groups: one received DC101 monotherapy at the same dose/ schedule as described above, the other received vehicle control. Studies were terminated when the tumors from the "doxorubicin followed by vehicle" group reached a size which necessitated euthanasia. Additional details, including specific mouse strains and number of animals per arm, are located in Supplementary Table 1.

Tumor volume was transformed to a log scale to equalize variance across time and treatment groups. Log volume data was analyzed with a two-way repeated measures analysis of variance by time and treatment using the MIXED procedures in SAS software (Version 9.3). The correlation model for the repeated measures was Spatial Power. Treated groups were compared to the control group at each time point. The MIXED procedure was also used separately for each treatment group to calculate adjusted means and standard errors at each time point. Combinations were defined as additive if the combination arm was statistically different from both of the single agent arms using the BLISS independence method. Waterfall plots were generated on the day prior to splitting of treatment groups or the last day the majority of vehicle animals were able to be evaluated prior to sacrifice.

\section{Abbreviations}

VEGFR1, vascular endothelial growth factor receptor 1; VEGFR2, vascular endothelial growth factor receptor 2; VEGFR3, vascular endothelial growth factor receptor 3; VEGF-A, vascular endothelial growth factor A; 
VEGF-B, vascular endothelial growth factor B; VEGF-C, vascular endothelial growth factor C; VEGF-D, vascular endothelial growth factor D; PlGF, placental growth factor; RMS, rhabdomyosarcoma; CDX, cell line-derived xenograft; PDX, patient-derived xenograft; DSRCT, desmoplastic small round cell tumor.

\section{Author contributions}

CDL: data assembly, data analysis and interpretation, and manuscript drafting and revision; WB: data collection and analysis; MD: data collection and analysis; MR: data collection and analysis; LW: data collection and analysis; JS: data collection and analysis; BP: conception and design; HW: data interpretation, manuscript revision; LFS: conception and design, data interpretation, manuscript revision; $\mathrm{BF}$ : conception and design, data analysis and interpretation, manuscript drafting and revision.

\section{CONFLICTS OF INTEREST}

All authors are full-time employees of Eli Lilly and Company.

\section{FUNDING}

This study was funded by Eli Lilly and Company, Lilly Corporate Center, Indianapolis, Indiana, USA.

\section{REFERENCES}

1. Jemal A, Ward EM, Johnson CJ, Cronin KA, Ma J, Ryerson B, Mariotto A, Lake AJ, Wilson R, Sherman RL, Anderson RN, Henley SJ, Kohler BA, et al. Annual Report to the Nation on the Status of Cancer, 1975-2014, Featuring Survival. J Natl Cancer Inst. 2017; 109:djx030. https://doi. org/10.1093/jnci/djx030. [PubMed]

2. Ou JY, Spraker-Perlman H, Dietz AC, Smits-Seemann RR, Kaul S, Kirchhoff AC. Conditional survival of pediatric, adolescent, and young adult soft tissue sarcoma and bone tumor patients. Cancer Epidemiol. 2017; 50:150-57. https:// doi.org/10.1016/j.canep.2017.08.015. [PubMed]

3. Ceschel S, Casotto V, Valsecchi MG, Tamaro P, Jankovic M, Hanau G, Fossati F, Pillon M, Rondelli R, Sandri A, Silvestri D, Haupt R, Cuttini M. Survival after relapse in children with solid tumors: a follow-up study from the Italian off-therapy registry. Pediatr Blood Cancer. 2006; 47:560-66. https://doi.org/10.1002/pbc.20726. [PubMed]

4. Bhakta N, Liu Q, Ness KK, Baassiri M, Eissa H, Yeo F, Chemaitilly W, Ehrhardt MJ, Bass J, Bishop MW, Shelton $\mathrm{K}$, Lu L, Huang S, et al. The cumulative burden of surviving childhood cancer: an initial report from the St Jude Lifetime Cohort Study (SJLIFE). Lancet. 2017; 390:2569-82. https:// doi.org/10.1016/S0140-6736(17)31610-0. [PubMed]
5. Adamson PC. Improving the outcome for children with cancer: development of targeted new agents. CA Cancer J Clin. 2015; 65:212-20. https://doi.org/10.3322/caac.21273. [PubMed]

6. Apte RS, Chen DS, Ferrara N. VEGF in Signaling and Disease: Beyond Discovery and Development. Cell. 2019; 176:1248-64. https://doi.org/10.1016/j.cell.2019.01.021. [PubMed]

7. Ferrara N, Adamis AP. Ten years of anti-vascular endothelial growth factor therapy. Nat Rev Drug Discov. 2016; 15:385403. https://doi.org/10.1038/nrd.2015.17. [PubMed]

8. Folkman J. Role of angiogenesis in tumor growth and metastasis. Semin Oncol. 2002; 29:15-18. https://doi. org/10.1053/sonc.2002.37263. [PubMed]

9. Oladipupo SS, Kabir AU, Smith C, Choi K, Ornitz DM. Impaired tumor growth and angiogenesis in mice heterozygous for Vegfr2 (Flk1). Sci Rep. 2018; 8:14724. https://doi.org/10.1038/s41598-018-33037-2. [PubMed]

10. Klein D. The Tumor Vascular Endothelium as Decision Maker in Cancer Therapy. Front Oncol. 2018; 8:367. https:// doi.org/10.3389/fonc.2018.00367. [PubMed]

11. Arnold D, Fuchs CS, Tabernero J, Ohtsu A, Zhu AX, Garon EB, Mackey JR, Paz-Ares L, Baron AD, Okusaka T, Yoshino T, Yoon HH, Das M, et al. Meta-analysis of individual patient safety data from six randomized, placebocontrolled trials with the antiangiogenic VEGFR2-binding monoclonal antibody ramucirumab. Ann Oncol. 2017; 28:2932-42. https://doi.org/10.1093/annonc/mdx514. [PubMed]

12. Jayson GC, Kerbel R, Ellis LM, Harris AL. Antiangiogenic therapy in oncology: current status and future directions. Lancet. 2016; 388:518-29. https://doi.org/10.1016/S01406736(15)01088-0. [PubMed]

13. Fontanella C, Ongaro E, Bolzonello S, Guardascione M, Fasola G, Aprile G. Clinical advances in the development of novel VEGFR2 inhibitors. Ann Transl Med. 2014; 2:123. https://doi.org/10.3978/j.issn.2305-5839.2014.08.14. [PubMed]

14. Wetmore C, Daryani VM, Billups CA, Boyett JM, Leary S, Tanos R, Goldsmith KC, Stewart CF, Blaney SM, Gajjar A. Phase II evaluation of sunitinib in the treatment of recurrent or refractory high-grade glioma or ependymoma in children: a children's Oncology Group Study ACNS1021. Cancer Med. 2016; 5:1416-24. https://doi.org/10.1002/cam4.713. [PubMed]

15. Maris JM, Courtright J, Houghton PJ, Morton CL, Kolb EA, Lock R, Tajbakhsh M, Reynolds CP, Keir ST, Wu J, Smith MA. Initial testing (stage 1) of sunitinib by the pediatric preclinical testing program. Pediatr Blood Cancer. 2008; 51:42-48. https://doi.org/10.1002/pbc.21535. [PubMed]

16. Maris JM, Courtright J, Houghton PJ, Morton CL, Gorlick R, Kolb EA, Lock R, Tajbakhsh M, Reynolds CP, Keir ST, $\mathrm{Wu}$ J, Smith MA. Initial testing of the VEGFR inhibitor AZD2171 by the pediatric preclinical testing program. 
Pediatr Blood Cancer. 2008; 50:581-87. https://doi. org/10.1002/pbc.21232. [PubMed]

17. Chisholm JC, Merks JH, Casanova M, Bisogno G, Orbach D, Gentet JC, Thomassin-Defachelles AS, Chastagner P, Lowis S, Ronghe M, McHugh K, van Rijn RR, Hilton M, et al, and European paediatric Soft tissue sarcoma Study Group (EpSSG) and the European Innovative Therapies for Children with Cancer (ITCC) Consortium. Open-label, multicentre, randomised, phase II study of the EpSSG and the ITCC evaluating the addition of bevacizumab to chemotherapy in childhood and adolescent patients with metastatic soft tissue sarcoma (the BERNIE study). Eur J Cancer. 2017; 83:177-84. https://doi.org/10.1016/j. ejca.2017.06.015. [PubMed]

18. Berthold F, Hömberg M, Proleskovskaya I, Mazanek P, Belogurova M, Ernst A, Sterba J. Metronomic therapy has low toxicity and is as effective as current standard treatment for recurrent high-risk neuroblastoma. Pediatr Hematol Oncol. 2017; 34:308-19. https://doi.org/10.1080/0888001 8.2017.1373314. [PubMed]

19. Lu D, Jimenez X, Zhang H, Bohlen P, Witte L, Zhu Z. Selection of high affinity human neutralizing antibodies to VEGFR2 from a large antibody phage display library for antiangiogenesis therapy. Int J Cancer. 2002; 97:393-99. https://doi.org/10.1002/ijc.1634. [PubMed]

20. Chau I, Peck-Radosavljevic M, Borg C, Malfertheiner P, Seitz JF, Park JO, Ryoo BY, Yen CJ, Kudo M, Poon R, Pastorelli D, Blanc JF, Chung HC, et al. Ramucirumab as secondline treatment in patients with advanced hepatocellular carcinoma following first-line therapy with sorafenib: patient-focused outcome results from the randomised phase III REACH study. Eur J Cancer. 2017; 81:17-25. https://doi. org/10.1016/j.ejca.2017.05.001. [PubMed]

21. Lowery CD, VanWye AB, Dowless M, Blosser W, Falcon BL, Stewart J, Stephens J, Beckmann RP, Bence Lin A, Stancato LF. The Checkpoint Kinase 1 Inhibitor Prexasertib Induces Regression of Preclinical Models of Human Neuroblastoma. Clin Cancer Res. 2017; 23:4354-63. https:// doi.org/10.1158/1078-0432.CCR-16-2876. [PubMed]

22. Falcon BL, Swearingen M, Gough WH, Lee L, Foreman R, Uhlik M, Hanson JC, Lee JA, McClure DB, Chintharlapalli $\mathrm{S}$. An in vitro cord formation assay identifies unique vascular phenotypes associated with angiogenic growth factors. PLoS One. 2014; 9:e106901. https://doi. org/10.1371/journal.pone.0106901. [PubMed]

23. Prewett M, Huber J, Li Y, Santiago A, O'Connor W, King K, Overholser J, Hooper A, Pytowski B, Witte L, Bohlen P, Hicklin DJ. Antivascular endothelial growth factor receptor (fetal liver kinase 1) monoclonal antibody inhibits tumor angiogenesis and growth of several mouse and human tumors. Cancer Res. 1999; 59:5209-18. [PubMed]

24. Gröbner SN, Worst BC, Weischenfeldt J, Buchhalter I, Kleinheinz K, Rudneva VA, Johann PD, Balasubramanian GP, Segura-Wang M, Brabetz S, Bender S, Hutter B, Sturm D, et al, and ICGC PedBrain-Seq Project, and ICGC MMML-Seq Project. The landscape of genomic alterations across childhood cancers. Nature. 2018; 555:321-27. https://doi.org/10.1038/nature25480. [PubMed]

25. Ma X, Liu Y, Liu Y, Alexandrov LB, Edmonson MN, Gawad C, Zhou X, Li Y, Rusch MC, Easton J, Huether R, Gonzalez-Pena V, Wilkinson MR, et al. Pan-cancer genome and transcriptome analyses of 1,699 paediatric leukaemias and solid tumours. Nature. 2018; 555:371-76. https://doi. org/10.1038/nature25795. [PubMed]

26. Zirlik K, Duyster J. Anti-Angiogenics: Current Situation and Future Perspectives. Oncol Res Treat. 2018; 41:166-71. https://doi.org/10.1159/000488087. [PubMed]

27. Ronca R, Benkheil M, Mitola S, Struyf S, Liekens S. Tumor angiogenesis revisited: regulators and clinical implications. Med Res Rev. 2017; 37:1231-74. https://doi.org/10.1002/ med.21452. [PubMed]

28. Imai K, Takaoka A. Comparing antibody and smallmolecule therapies for cancer. Nat Rev Cancer. 2006; 6:714-27. https://doi.org/10.1038/nrc1913. [PubMed]

29. Kieran MW, Kalluri R, Cho YJ. The VEGF pathway in cancer and disease: responses, resistance, and the path forward. Cold Spring Harb Perspect Med. 2012; 2:a006593. https://doi.org/10.1101/cshperspect.a006593. [PubMed]

30. Itatani Y, Kawada K, Yamamoto T, Sakai Y. Resistance to Anti-Angiogenic Therapy in Cancer-Alterations to AntiVEGF Pathway. Int J Mol Sci. 2018; 19:E1232. https://doi. org/10.3390/ijms19041232. [PubMed]

31. Zarrin B, Zarifi F, Vaseghi G, Javanmard SH. Acquired tumor resistance to antiangiogenic therapy: mechanisms at a glance. J Res Med Sci. 2017; 22:117. https://doi. org/10.4103/jrms.JRMS 182 17. [PubMed]

32. Falcon BL, Chintharlapalli S, Uhlik MT, Pytowski B. Antagonist antibodies to vascular endothelial growth factor receptor 2 (VEGFR-2) as anti-angiogenic agents. Pharmacol Ther. 2016; 164:204-25. https://doi.org/10.1016/j. pharmthera.2016.06.001. [PubMed]

33. Falcon BL, O'Clair B, McClure D, Evans GF, Stewart J, Swearingen ML, Chen Y, Allard K, Lee LN, Neote K, McEwen DP, Uhlik MT, Chintharlapalli S. Development and characterization of a high-throughput in vitro cord formation model insensitive to VEGF inhibition. J Hematol Oncol. 2013; 6:31. https://doi.org/10.1186/1756-8722-6-31. [PubMed] 